\title{
The Changing Faces of the Math Student: Images in U.S. Early Elementary Mathematics Textbooks, 1904-1999
}

\author{
Maryellen Schaub ${ }^{*}$, Daniel Salinas ${ }^{2}$, Samira Halibi ${ }^{3}$, David Baker ${ }^{1}$ \\ ${ }^{1}$ Education Policy Studies, Penn State University, University Park, USA \\ ${ }^{2}$ Organization for Economic Country Development, Paris, France \\ ${ }^{3}$ World Bank, Washington, DC, USA \\ Email: mxs88@psu.edu
}

\begin{abstract}
This study explores the historical changes throughout the 20th century in the visual hidden curriculum contained in early elementary mathematics textbooks in the U.S. The study is based in a quantitative content analysis of iconic images published in early elementary mathematics textbooks between 1904 and 1999. Data come from coding of an archive of 15,901 pages from 32 mathematics textbooks widely used in the U.S. Main findings reveal that, compared with mathematics textbooks used early in the century, contemporary mathematics textbooks include significantly more images, make a more intensive use of images of people, are more inclusive of social identities traditionally excluded or represented through stereotypes (e.g. women, racial/ethnic minorities), and portray young students not merely as passive recipients of information but as active learners able to perform cognitively complex mathematical tasks. As schooling expanded over the 20th century, textbook images evolved to include new socially constructed meanings of student.
\end{abstract}

Keywords: Visual hidden curriculum, schooling expansion, social identities.

\section{Introduction}

Textbooks are studied for their explicit curricular content, and also as powerful representations of culture. The cultural content is both the text and images, it is what is included and what is left out, it is messages about human society transmitted from the textbook to the reader. This content is frequently referred to as a "hidden curriculum," a component of multimodality in pedagogical communication with its own messages to the learner in addition to the official curriculum [1][2][3][4]. A central aspect of the textbook's hidden curriculum is messages communicated through visual content. Along with a general "semiotic revolution" in all public texts, including electronic media, newspapers, magazines, and advertising, academic textbooks experienced a similar visual sea change over the 20th century. Often rich in subtle, and not so subtle, cultural messages about the subject, the student, the world, and the learning process, this visual modality in textbooks represents a major avenue to increase our understanding of the array of messages that can influence learners.

A vigorous interdisciplinary field of research has emerged arguing that the visual is a key dimension of social life, including its material conditions, and involves a consistent aesthetic and iconic flow of messages [5][6][7]. The same is true for images in academic textbooks. And there is parallel inquiry into the historical changes in textbook visual content, from which five overarching conclusions contextualize the current investigation [8][9]. First, prior to the $19^{\text {th }}$ century textbooks contained few images, then over the next two centuries with growing print technology images become common, increasing both in frequency and graphical sophistication, such as with the addition of color and photographs [10]. Second, this visual revolution occurred for all levels of schooling, but has been the most intense in primary school textbooks [11]. Third, the historical increase in graphic content is evident in all subjects, so that even mathematics and science textbooks have been transformed by visual "tools for thinking" with pictures and photographs along with tables and diagrams [12][11]. Fourth, the historical record of images shows a lag between social change and the portraying of greater diversity in American society [10]. Finally, there is an ongoing debate over the educational value and meaning of images in the learning process [13][14][15][16]. 
In addition to these conclusions about the hidden curriculum of images, a broader contextualization of the analysis below comes from the historical changes in mathematic textbooks content, a topic that only recently received systematic historical inquiry. Employing the same archive as analyzed here, an extensive content analysis of thousands of pages sampled from hundreds of widely used elementary school mathematics textbooks published over the $20^{\text {th }}$ century reveals several important overarching trends [17] [18] [19] [20]. Textbooks in the early part of the century were shorter and narrower in breath of content but moved to substantial amounts of advanced arithmetic quickly. By the middle of the century less advanced topics were presented and problem-solving tasks were simplified. From the mid1960s onward, however, this trend reversed with significant expansion of topics and the number of pages. There was a parallel increase in the amount of material on reasoning consisting of pattern solving, informal algebra, informal geometry, digit-symbol substitution, probability, and grouping/categorization, as well as a shift of traditionally more advanced topics from higher to lower grades. Textbooks of the last 35 years did not require as much rote drill and mechanical application of algorithms and memorization of arithmetic facts, and a cognitive assessment of the mathematical content found that abstract conceptualization of problem-solving strategies for basic arithmetic, and effortful reasoning approaches increased. Similar findings have been recently reported for a parallel study of reading and language arts textbooks for primary school [21]. Contrary to conventional wisdom, the American elementary mathematics curriculum of the late $20^{\text {th }}$ century became both more mathematically and cognitively demanding than in earlier periods. Although an important context, textbook content is closer to the formal or intended curriculum, the academic knowledge that students are supposed to learn, while images in textbooks as hidden curriculum are transmitters of culture [22].

Along with conclusions from prior research, there are several contrasting theoretical perspectives about the hidden curriculum in textbooks and culture broadly defined. The popular theory of political hegemony argues that the content of school textbooks is a means of social control that reflects the interests of dominant groups and reproduces the existing social order [23][24][25]. Proponents of this view hypothesize that American textbooks in the 19 th and early $20^{\text {th }}$ century played a culturally conservative role. As schooling expanded, textbook content reinforced an illusion of opportunity for all through their patriotic celebration of the virtues of the new American nation and their contribution to the processes of nation-building and assimilation of immigrants [26][27]. Research from this theoretical perspective shows that historically textbooks in the U.S. have celebrated individuality and equal opportunity and ignored social class inequality as well as other stratifying characteristics such as race, ethnicity and gender [28][29][30].

In contrast, the counter-hegemonic theory argues that textbook content is an arena of social conflict where cultural and political actors struggle for a platform. From this perspective, textbook content is a vehicle for obtaining recognition and legitimacy, and can convey political ideas aimed at promoting socially progressive change [31]. For example, conflicting world views clashed in the controversies around science textbooks throughout the $20^{\text {th }}$ century [32]. As schooling expanded over the $20^{\text {th }}$ century in the United States, competing groups struggled for control and textbook content slowly diversified [33][34][35][36][37]. Proponents of this view point to the 1960s when textbook content became sensitive to racial differences, leaving behind the emphasis on assimilation into the white, middle-class that had characterized the textbooks of previous decades [27][25]. In the latter part of the $20^{\text {th }}$ century, backlash from this content evolution led some activist groups to argue that textbooks now incorporate too many social problems [32] or use a "quota" approach [38]. Both of these political approaches characterize textbooks as an arena in which special interests of social or activist groups work to control the content and imply that content can be not only oppressive or coercive but also a representation of political movements.

Besides overtly political theories of hidden curriculum is theory on the social power of education as an institution itself and its direct influence on culture, which can be applied to hidden curriculum [39]. Formal education is not merely a derivative institution, rather it also has an independent effect on contemporary culture, and this is hypothesized to be also so for its hidden curriculum. With the rapid unfolding of the worldwide revolution in access to schooling and the extensive culture of education it has produced, instruction, curricular content, and textbooks reflect social change within education itself. As schooling expanded to include larger proportions of the American population over the $20^{\text {th }}$ century, the norms and values of schooling as an institution evolved and were likely a force in decisions about the images found in textbooks. For example, research on textbook publishers indicates that the companies 
often respond to the wishes of educators over political and social groups [40]. Committees made up of professionals review and approve acceptable textbooks based largely on organization, presentation and pedagogy, and studies suggest that the "aesthetics of school textbooks" becomes very important in committee choices [41].

Related studies have highlighted how textbook content reflects global social trends and ideas beyond local contexts. For example, historical changes in textbook treatment of such topics as the natural environment, human rights, or the Vietnam War are related to national drift towards global social norms [42][43][44][45]. In general, these studies show that textbook curricular and cultural content spread globally, as similar messages about students and subject areas are present worldwide. For example, a recent study of historical changes in textbooks' curricular and cultural dimensions assembled and analyzed a collection of over 400 social studies and civics textbooks from about 70 countries covering from 1970 to 2008. It revealed a global rise in the later part of the $20^{\text {th }}$ century of educational emphasis on human rights, environmentalism, and "student-centrism", i.e. the "degree to which the textbook appealed to the student's interests, capacities and choices" [43] p7. In a similar vein, McEneaney [45] used a sample of science and math textbooks from 57 countries to show how instructional materials reflect a global trend of expansion of the notion that students at early stages of their school training are actors capable of performing increasingly complex mathematical and scientific activities, and that primary school science is literally "peopled" with textbooks devoting much space to depictions of people doing and benefiting from science. Textbooks show a significant increase in the depiction of ordinary people - including women and racial minorities - doing science and math, subjects increasingly portrayed as activities in which all can engage.

These theories and related analyses suggest that textbooks are likely carriers of normative content about larger political, social and educational cultural ideas, and this normative content can dynamically blend and change over time. The latter of which can be summarized as dimensions of school textbooks' hidden curriculum cultural content that have organized historical struggles for progressive change in American schooling: social inclusivity -the pursuit of equal education opportunity to all children regardless of gender or racial background- and the institutional power of education on ideas about students' cognitive empowerment - the promotion of child-centered, constructivist pedagogical methods that invite students to engage in effortful thinking and be more active in their pursuit of formal curriculum. Yet most of this prior theory and research is limited to just the written content, less studied is how the images in textbooks and their powerful impact on understanding play a role in this historical process.

Analyzed here are historical changes over the 20th century in images contained in US early elementary mathematics textbooks as schooling expanded both upward to older students and downward to include younger students as the number of years of formal schooling expanded and a larger proportion of the population went to school. All images, with the exception of technical visual elements such as equations and geographical shapes, are qualitatively and quantitatively assessed along the two core cultural ideas of social inclusivity and students' cognitive empowerment. Specifically, the analyses examine if images, and particularly those of people, become more frequently displayed in math textbooks over time, and at which periods. Have patterns of social inclusion for females and racial minorities changed over time? Do the activities of the people pictured evolve in the context of learning mathematics? And, is the expected role of student in the mathematics process represented as one of passive learning or active cognitive engagement?

The results show an overall trend toward more progressive values in the images of mathematics textbooks over the $20^{\text {th }}$ century, as measured by the growing frequency of images depicting people in ways that convey messages of social inclusion and cognitive empowerment. As schooling expanded over the $20^{\text {th }}$ century, textbook content evolved with the socially constructed notions of gender, race and ethnicity, as well as the very essence of the meaning of student. After the detailed findings are presented, they are situated in the context of the above summary of theory and prior research.

\section{Research Design}

The assessment of images across a unique archive of systematically coded 15,901 pages from 32 widely used kindergarten to 3rd grade school mathematics textbooks published between 1904 and 1999 provides 
an unusually representative and historically extensive view of the visual hidden curriculum in textbooks. As employed here, content analysis of images explicated through a quantitative summary is a standard methodology in visual research [46][47]. Less in-depth than some qualitative semiotic approaches, it has the advantage of identifying long-term, broad historical trends that often lead to substantial change in education [48]. This strategy is in distinct contrast to earlier studies of textbooks' hidden curricular content that are based on in-depth qualitative analysis (e.g. critical interpretation of historical documents) of a small number of textbooks from restricted time periods. Also, by studying images in mathematics textbooks the analysis extends and balances out previous research that is limited to ideological struggles in the more obviously contentious fields of history, social science, and literature [27][49][28].

Images have increased for textbooks of all grade levels and all subject areas but have been the most dramatic in primary school textbooks [11] so that even mathematics and science textbooks have been transformed [12][11]. We, therefore, considered mathematics textbooks for early elementary education, that is, kindergarten through $3^{\text {rd }}$ grade because they simultaneously are the most effected grades by the increase while also representing a subject that historically contained less images. This is a key period in the cognitive and attitudinal development of the child, and thus it represents an important period to observe the value-content of images in textbooks in a curricular area that was intensifying in both cognitive demand and student-centeredness, especially over the last four decades of the century. The extent to which our findings are influenced by this focus on materials directed towards younger students is an empirical question open to further research; however, it seems likely that the broader cultural constructs influencing education that we report on in this paper might apply similarly to textbooks designed for both early elementary and further educational levels.

\section{$2.1 \quad$ Textbook Selection}

Our analysis is based on a sample of $32 \mathrm{~K}-3$ mathematics textbooks published during the 20th century in the United States drawn from a larger, existing archive of mathematic textbooks that was created and used in the recent analysis of curricular change [17]. This larger archive includes 141 kindergarten through 6th grade mathematics textbooks from 33 different series (i.e., sets of texts prepared by the same publisher and designed to span the elementary grades) from 10 different publishing companies from 1904 until 2000. The textbook series, not publishers per se, were selected. The goal of the archive was to ensure that the sampled series and their texts included in the archive represented those that had broad distribution, and hence, broad nationwide influence. Because neither sales records nor adoption records could be used to identify the most widely-used books in all periods, three alternate strategies guided the sampling of textbooks:

1) Publication run. Poorly received texts are unlikely to remain in print for an extensive period of time; therefore, only multi-year publication runs of texts and series of texts were considered in the sample. The Bowker's Annual Elementary and High School Textbooks in Print was used to identity multi-year publications.

2) Expert list. The list of texts meeting the first multi-year publication runs criteria was further evaluated for its historically representativeness across the century by a mathematics education expert, two education historians, and two archivists. ${ }^{1}$ The evaluation led to some additions and no subtractions. 3) Additional documents. For additional cross-reference of the list obtained after the two previous steps, we used references to required texts from available mathematics courses of study from districts and states (for earlier periods) and state adoption lists and standards documents from districts and states (for later periods).

As additional criteria, experimental textbooks were not included in the archive because they tended to be used by small numbers of the nation's students at any given time, and experimental curricula were often substantially different from the commercial textbooks most students in the nation were exposed to at the time. As such, they would not be representative of widely-used textbooks. This means that our sample does not necessarily represent the range of different textbooks that where available at any moment, but rather textbooks that conveyed the mainstream cultural and educational values in American schools throughout the century. Thus, while this is not a random selection of texts, the above

\footnotetext{
${ }^{1}$ The expert was a Distinguished Professor Emeritus of Math Education at Illinois State University.
} 
criteria and procedures provide support to the claim that the sample of mathematics textbooks contained in the archive is a valid representation of the modal textbooks in the nation, while at the same time recognizes diversity among the most commonly used textbooks as multiple textbooks were selected for each time period.

\subsection{Periodization}

The time periods used for our analysis are as follows: 1904-1921, 1924-1931, 1932-1948, 1948-1963, 19641971, 1974-1978, 1981-1991, 1991-1999. Instead of decades, substantive periods were chosen for two main reasons: 1) the periods reflected cycles of curricular change and also had the most consistency across textbook series within intervals, and 2) to ensure comparability with the curriculum content analysis already reported [17]. Arranging the century by decade reflected neither well-established periods of curricular reform nor the market availability of textbook series as shown in publication runs. Nearly every time period is separated by a clean break in publication dates, suggesting the periods may align with significant periods of curricular and educational change. Therefore, in order to remain competitive in the market, most major publishers tended to release a new text to match the new expectations ${ }^{2}$.

We did not include textbooks published after 2000 because the timeframe of the original archive was restricted to observe variation across the $20^{\text {th }}$ century. The similarity found in modal contemporary textbooks in terms of the main trends reported in this analysis made it unnecessary to include an additional number of textbooks for the final periods (for the final 20 years going from 1980 to 2000 five different textbooks were included in the sample).

\subsection{Coding Strategy}

Every page in every textbook in the sample was coded according to the following strategy. First, we measured the frequency of visual content by coding each page for whether or not it contained an image $(1=$ includes image, $0=$ does not include image). For the purposes of coding, analyzed images were defined as any visual element that was not a number, equation, geographical shape, word, or a graph; usually they were illustrations and photographs that often, but not always, included frames, headlines and/or captions. We analyzed whether the use of visual content in mathematics textbooks has become more or less frequent over time by comparing textbooks of different periods in terms of the proportion of pages that contain images. This is a more general measure of the importance of visual content in mathematics, compared with more specific and time-consuming alternative measures such as area within the page [50], but it has the advantage of being an efficient measure to code a high amount of textbook pages $(15,901)$ in order to compare across a long period of time.

Second, we measured the "peopling" of the visual content (i.e. the frequency of people appearances in images) by considering each page with an image and coding 1 if the image contained people and 0 if it did not (e.g. fish swimming). Code 1 considered images that included either a single person -of any age and of any gender and race/ethnicity- or more than one person.

Third, for those images that included people we counted and coded for gender and race. Because it was often difficult to determine what specific race/ethnicity a person belonged to, we categorized race as white and non-white, a simplified measure that still captured the main distinction of interest. To measure participation or inclusion of non-whites, for each image containing people we counted the exact number of individuals from each racial category (non-white or white). In the case of gender, the coding categories were female and male, and we followed a similar counting procedure. Binary gender differences were usually apparent through stereotypical signals such as haircuts (e.g. longer and/or fringes in females), clothing items (e.g. dresses, skirts, high-heeled shoes, hair ties for females, tie and bow ties for males, etc.), mustaches in males, etc. In cases where gender attribution between female and male was not obvious, we checked the written text or other visual elements in the textbook page that could provide contextual elements for classification. In the few cases when clear gender (or racial)

\footnotetext{
${ }^{2}$ To be conservative in estimating patterns across time periods, there are gaps between some periods because no texts met the sampling criteria. The calculated coefficients of variation (C.V.) across textbooks' in topical coverage for each period demonstrate that variation within periods is minimal, indicating reasonable content uniformity within periods.
} 
identification was impossible (e.g. no visual or textual clues, children wearing masks, etc.) cases were not counted. The gender diversity of images included in the textbooks is not so large as to include explicit signals that could be attributed to homosexual or transgender sexual identities; this might be seen as supporting the notion that mathematic education in the United States has under-theorized and uncritically reinforced binary gender differences [51].

60

\section{ADDITION}

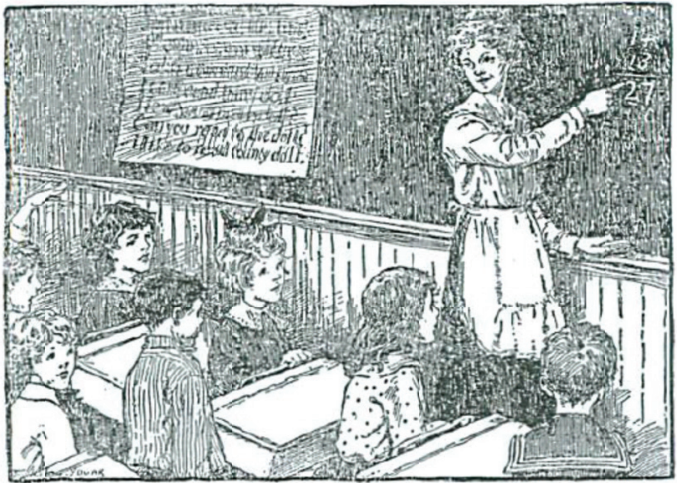

Figure 1. Passive math (Wentworth School Arithmetic, 1920)

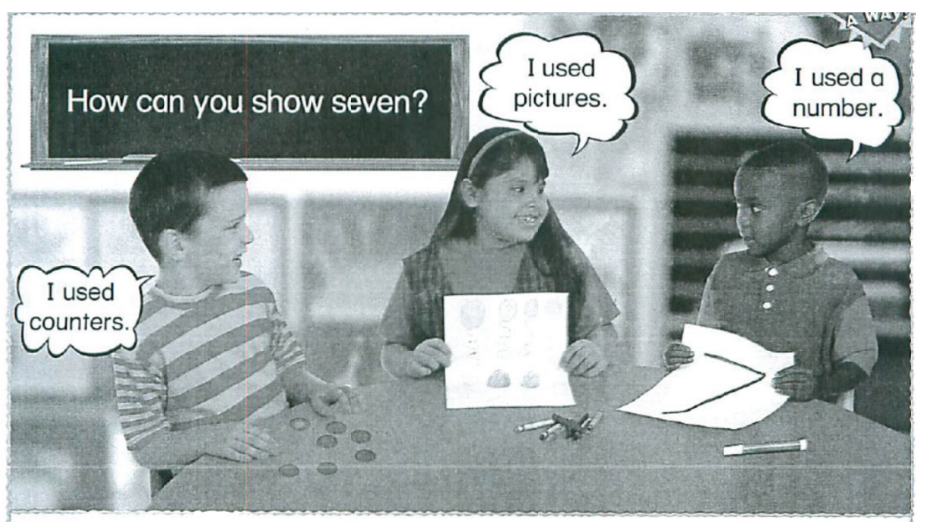

Figure 2. Active math (Silver Burdett Ginn, 1999, Gr.1, p.19)

Finally, we developed three codes to categorize what the people in the images were doing based on the activity's relationship to math as shown in Figures 1-3. The mutually exclusive codes were defined as follows: 1) passive math, where people are pictured as merely receiving mathematical information or surrounded by activities that may involve math but without actual engagement in them; for example, passively sitting in a classroom (watching the teacher), playing games that have numbers but do not require the use of any math operation to play (like dominos), holding math-related tools (rulers, coins, geometrical figures) but not actually using them, shopping in a store (but not ciounting), or standing and attending at a lemonade stand (but not making change); 2) active math, where children are pictured as being directly and personally involved in mathematical activity, such as thinking about possible methods to solve a math problem, playing number games that involve addition or subtraction, and measuring or counting things. This second category is a proxy measure of cognitive empowerment, the invitation to children to assume an active involvement in their own learning process; and 3) unrelated to math, where people are engaged in non-mathematical activities, such as playing with animals in a farm, dancing, having a picnic, or simply not engaged in any activity. Figures 1 and 2 show examples of pictures coded as passive math and active math respectively. Figure 1 depicts large group, teachercentered instruction of factual information delivered to students - white boys and girls- who passively listen; Figure 2, in contrast, shows a small diverse group of students who appear as the active agents in 
the application of mathematical concepts. In contrast, images like Figure 3, which represent boy scouts camping and girls at a table, would be coded as an image unrelated to math. These codes were developed in an iterative process moving from the concepts defined above to images from textbooks (about a 10\% sub-sample) and then back again to concepts. This yielded a coding scheme with high face validity and grounding in the conceptual ideas leading the analysis.
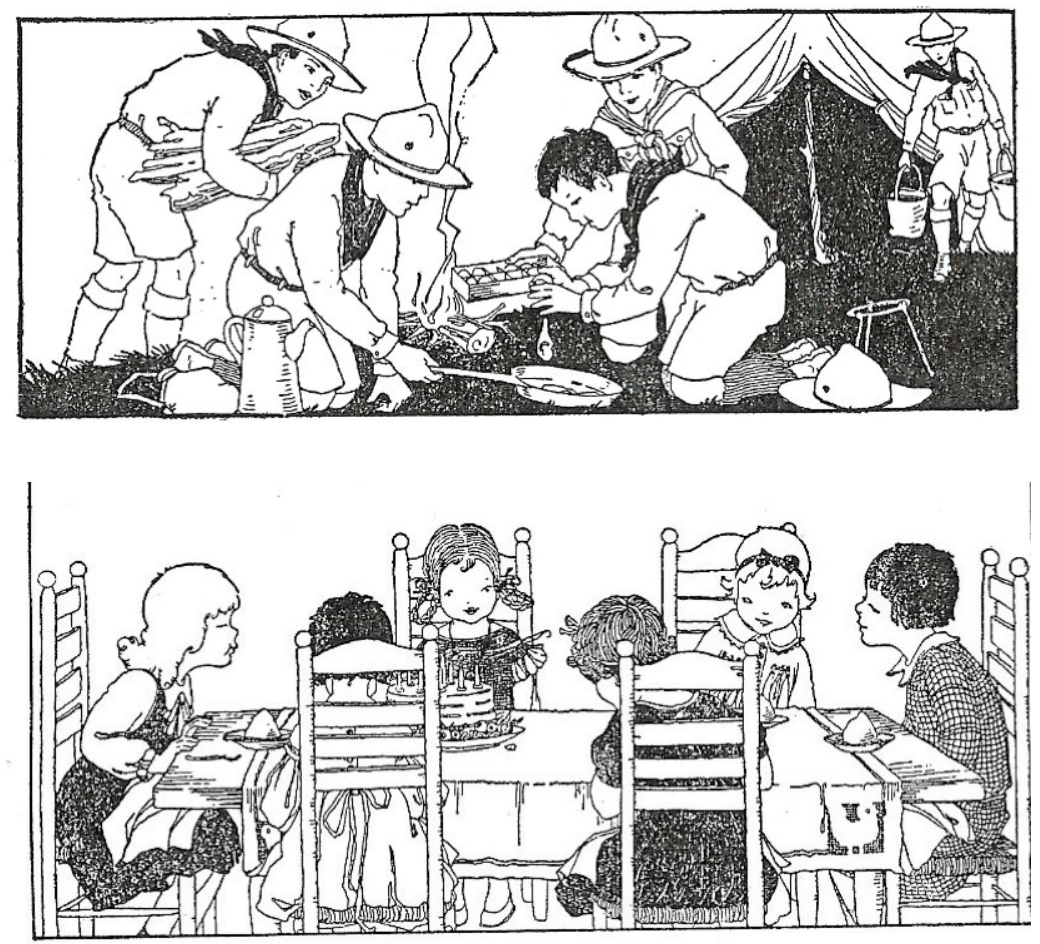

Figure 3. Unrelated to math (the Smith-Burdge Arithmetics, Primary Book, 1926, Wentworth-Smith Mathematical Series, Ginn and Company, p.316 and 259)

Following standard procedures of content analysis methodology, a team of four coders was trained on the coding scheme that included all variables and codes described above (frequency of images, people, race, gender and activity's relation to math) and practiced on textbooks not in our sample from a range of historical periods [47]. A coding guide and training sessions for coders were developed to ensure that activities were coded consistently across textbooks. A sub-sample of $20 \%$ of all coding assignments were set aside for multiple coding for estimating inter-coder reliabilities, which were calculated by Fleiss's Kappa of the ratio between observed agreement and expected agreement and ranged from an acceptable agreement level of .8 to .9. Then each textbook was coded by a first coder, and then verified by a second coder. Any discrepancies in coding were resolved by consensus with a third coder, and a principal investigator. For the analysis, data was aggregated by book and then by period to calculate means for each period. T-tests determined whether the differences observed between periods were significant at the .05 level.

\section{Results}

Statistical analysis of the coded data uncovers three basic historical trends in the hidden curriculum of visual content of early elementary math textbooks across the century as displayed in Figure 4 . The top line shows an overall pattern of growth in the mean number of textbook pages; the middle line shows a steady increase in the mean frequency of visual content; and the bottom line shows after some "depeopling" of images from 1948 to 1970, a rise in the mean frequency of images of people through the rest of the century. See Appendix B for descriptive statistics of the distribution of qualities of textbooks and images for each time period. 


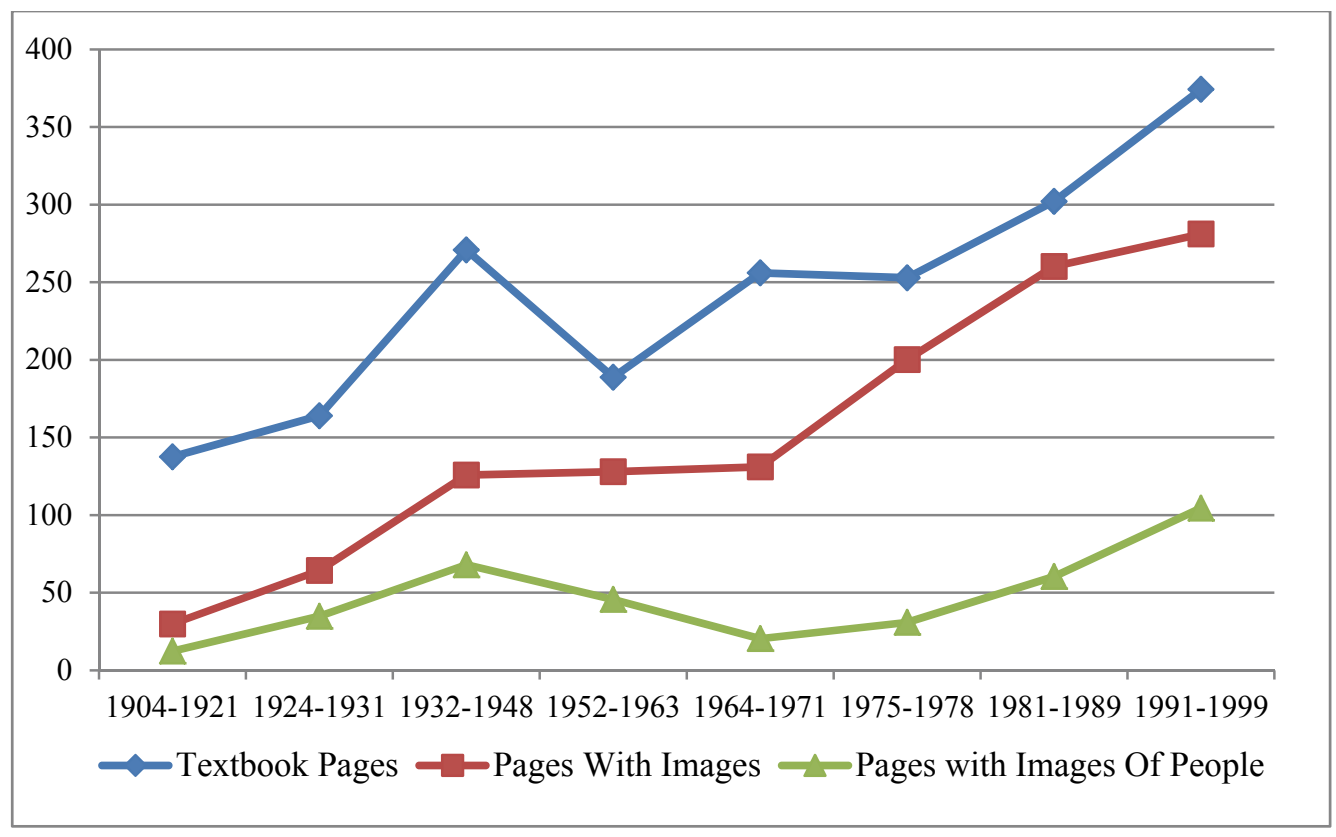

Figure 4. Mean number of textbook pages, pages with images, and pages with images of people in math textbooks, grades K-3, 1904-1999

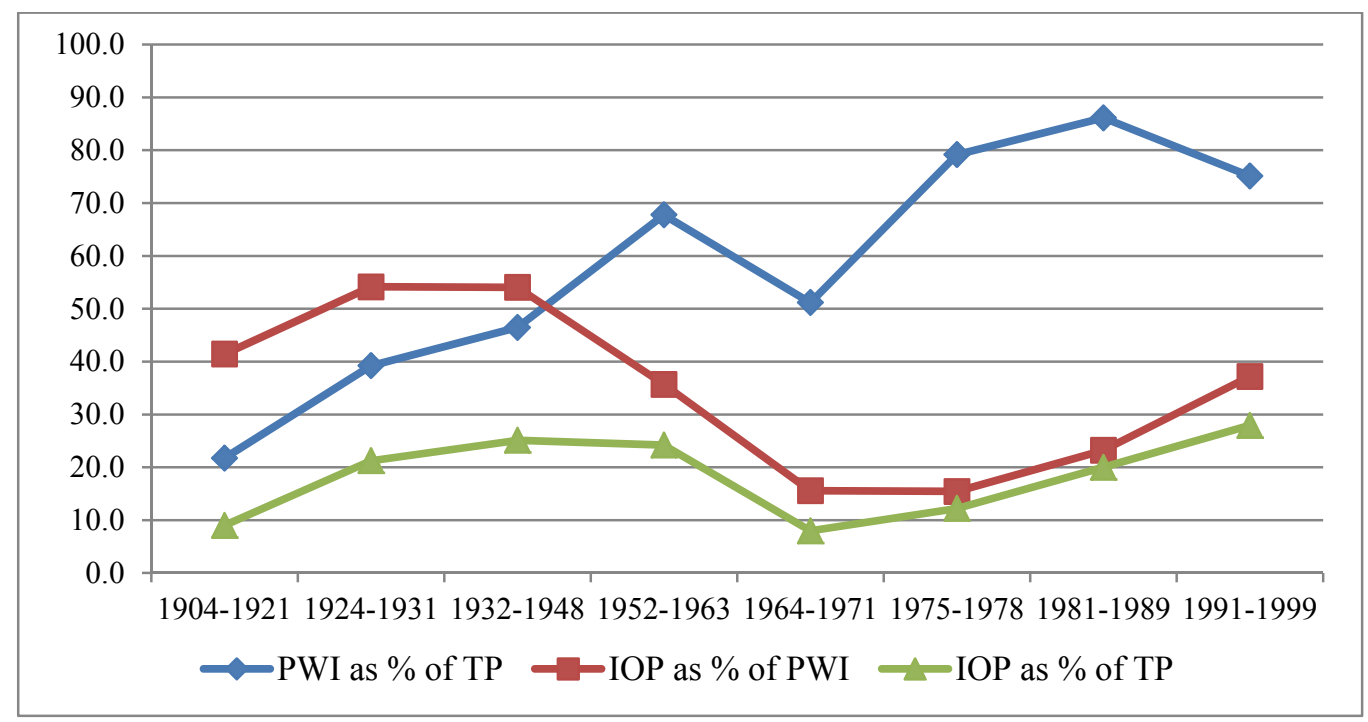

Figure 5. Percent of textbook pages with at least one image (PWI); percentage of textbook pages with images at least one person (PIP); percent of textbook pages image of one person (IOP); grades K-3, 1904-1999

The mean size of commonly used math textbooks increased across the $20^{\text {th }}$ century, and as it grew so did the frequency of visual content. In the first two decades, the average math textbook consisted of 138 pages and grew to 374 pages by the 1990's (a mean difference between the two periods $t=-5.108$, $\mathrm{p}=.0001)$. And in the earliest period (1904-1921) this average textbook included an image on 30 of its pages, while in by the 1990's the average textbook had 281 pages displaying an image. Figure 5 demonstrates interactions among these main trends. The small-squared line plots the percent of total pages with at least one image showing that early in the century textbooks had an image on only a mean of $22 \%$ of its pages, but the 1990 's $75 \%$ of pages included at least one image $(\mathrm{t}=-8.709, \mathrm{p}=.0001)$. As displayed in the 1907 example in Figure 6, early century textbooks were mostly text with some 
augmentation by images; a semiotic environment that would be strange to contemporary young students who are presented texts rich in visual content on mostly every page. ${ }^{3}$

\begin{tabular}{|c|c|c|c|c|c|}
\hline \multirow{4}{*}{\multicolumn{6}{|c|}{$\begin{array}{l}\text { 30. A man owned a farm of } 640 \text { acres and sold } 165 \\
\text { acres. How many acres had he left? } \\
\text { 31. A playground is } 225 \mathrm{ft} \text {. long and } 106 \mathrm{ft} \text {. wide. } \\
\text { How many feet longer than wide is the playground? } \\
\text { 32. The attendance at a school on Monday was } 592 \text {, and } \\
\text { on Tuesday it was } 548 \text {. How many pupils were absent } \\
\text { Tuesday? } \\
\text { 33. There are } 365 \text { days in a year. After } 259 \text { days have } \\
\text { passed, how many days is it until the end of the year? } \\
\text { 34. From } 500 \text { take } 236 \text {. }\end{array}$}} \\
\hline & & & & & \\
\hline & & & & & \\
\hline & & & & & \\
\hline \multirow{2}{*}{\multicolumn{6}{|c|}{$\begin{array}{l}\text { Take } 1 \text { hundred from the } 5 \text { hundreds and change it to } \\
10 \text { tens. Take } 1 \text { ten from the } 10 \text { tens ard change it to } 10 \\
500 \text { ones. Then } 6 \text { ones from } 10 \text { ones leaves } 4 \text { ones } \\
\frac{236}{264} \text { tens from the remaining } 9 \text { tens leaves } 6 \text { tens. } \\
2 \text { hundreds. The remaining } 4 \text { hundreds leaves } \\
\text { hom is } 264 \text {. }\end{array}$}} \\
\hline & & & & & \\
\hline \multirow{2}{*}{\multicolumn{6}{|c|}{ Subtract: }} \\
\hline & & & & & \\
\hline 1. & 2. & 3. & 4. & 5. & 6. \\
\hline $\begin{array}{l}300 \\
128\end{array}$ & $\begin{array}{l}400 \\
237\end{array}$ & $\begin{array}{l}500 \\
345\end{array}$ & $\begin{array}{l}600 \\
471\end{array}$ & $\begin{array}{l}700 \\
554\end{array}$ & $\begin{array}{l}800 \\
249\end{array}$ \\
\hline 7. & 8. & 9. & 10. & 11. & 12. \\
\hline 607 & 405 & 306 & 407 & 504 & 601 \\
\hline 219 & & $\underline{128}$ & 138 & & \\
\hline 13. & 14. & 15. & 16. & 17. & 18. \\
\hline $\begin{array}{l}710 \\
509\end{array}$ & $\begin{array}{l}851 \\
642\end{array}$ & & $\begin{array}{r}423 \\
219\end{array}$ & $\begin{array}{l}907 \\
115\end{array}$ & $\begin{array}{l}811 \\
602\end{array}$ \\
\hline
\end{tabular}

Figure 6. A textbook with no images (New Elementary Mathematics, Wentworth-Smith Mathematica Series, Ginn and Company, 1907, p65)

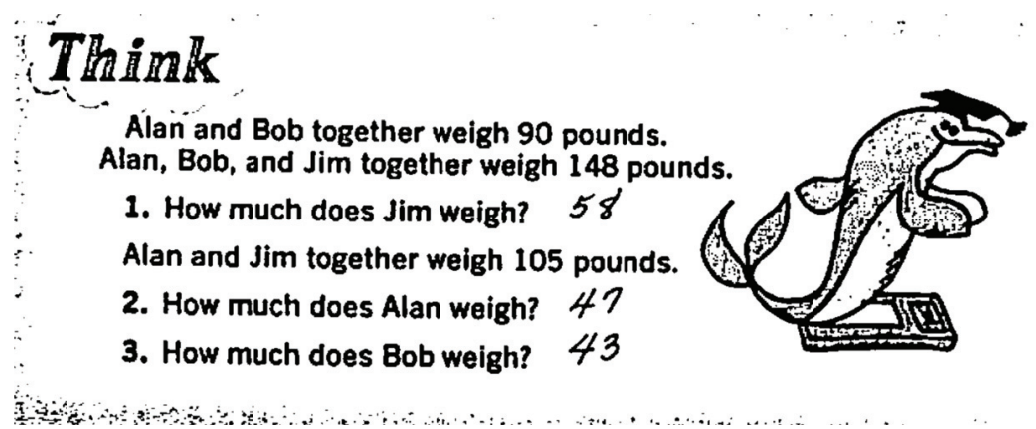

Figure 7. An example of the replacement of people by animals (Elementary School Mathematics, 1971, grade 3)

The richer semiotic environment also became more peopled, although this was not a steady linear process. Textbooks early in the century had a mean of only 12 images that included people, while by the 1990's this increased almost 9 times to 105 peopled images $(t=-5.048, \mathrm{p}=.001)$. As shown in the pyramided line in Figure 5, young students studying math in the first two decades of the century encountered images of people on only $9 \%$ of pages, while their counterparts at the end of the century saw peopled images on almost a third of the pages of a much expanded textbook. However, peopled images did not increase steadily across the century, as these kinds of images increased during the first half of the century, but declined from the late 1940s until 1971, and then began a steady increase to the end of the century. As shown in the large-squared line in Figure 5, the overall proportion of peopled images among all images began at about $40 \%$ then fell and rose back to that level over the course of the century. The decrease in the period 1964-1971 is a significant reduction from all the previous periods combined $(\mathrm{t}=2.743, \mathrm{p}=.009)$, and more noticeable given that during that period the number of pages and the number of images in textbooks increased overall. During this period, images of people were

\footnotetext{
${ }^{3}$ This is likely a conservative estimate of the expansion since textbooks from the early $20^{\text {th }}$ century frequently included more than one grade, a practice that disappeared as the century progressed.
} 
sometimes replaced by images of objects and other kinds of non-human, but more often of animals with human features (e.g. dressing) and performing human roles, such as the dolphin teaching in a 1971 textbook shown in Figure 7.

\subsection{Social Inclusivity of Peopled Images}

The eventual increase of the peopled image on math textbook pages came with an increase in the diversity of people pictured. Figure 8 shows the trends in the depiction of non-white people and females. As the diamonded line shows, starting in the1964-1971 period and on into the following periods the racially/ethnically diversity of images steadily increases. Up to that point the images were predominately white, and as shown in the 1930 example in Figure 9 included degrees of cultural appropriation such as what appears to be white boys pretending to be Native American in dress and in behavior as part of a counting lesson that used the popular children's rhyme, 'Ten Little Indian Boys'.

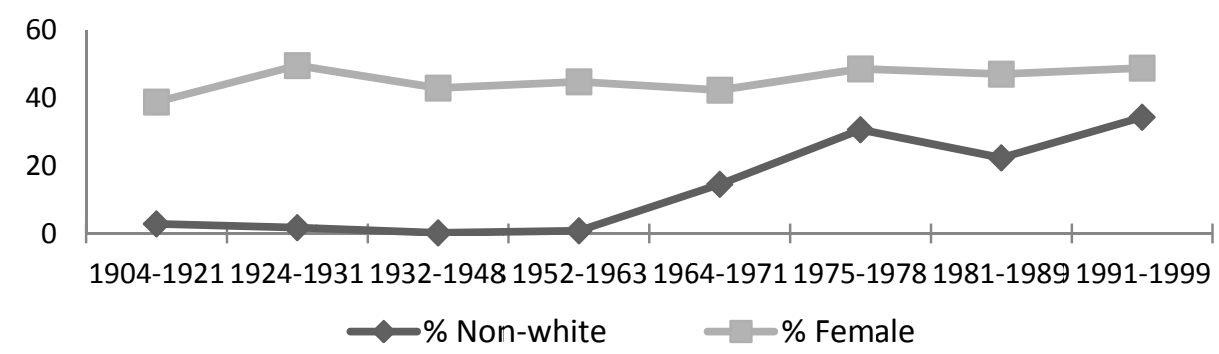

Figure 8. Inclusion of images of non-whites and females as a percentage of total images, 1904-1999, grades K-3

\section{TEN LITTLE INDIAN BOYS}

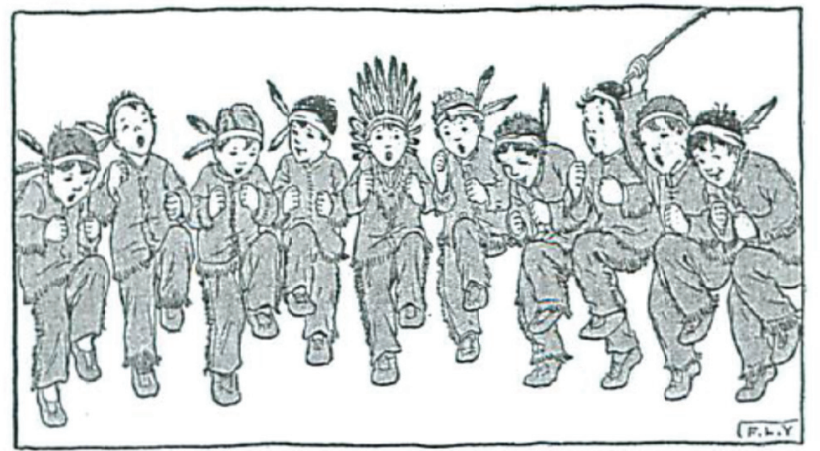

Figure 9. An example of stereotypical minority representation from the early part of the $20^{\text {th }}$ century. (Number Games and Stories, 1930)

By the latter part of the $20^{\text {th }}$ century there is a distinct increase in absolute and proportional amounts of visual representation of blacks, Asians, and Hispanic, while images such as that in Figure 9 disappeared entirely. The 1999 textbook image in Figure 2, (described earlier as an example of "active math") also exemplifies the increase in racial/ethnic diversity of learners. This image portrays a counting lesson that not only requires students to think about different representations of the number, which, when compared to memorizing and repeating a rhyme, is a more sophisticated learning strategy, but also the learners are more racially diverse.

Images of females appeared as often as images of males over the century as shown by the largesquared line in Figure 8. Behind this there is some inequality in what each gender was doing in pictures earlier in the century. While girls are shown in schools and school settings, they are often pictured engaged in feminized activities, such playing with dolls while boys are frequently shown in "masculine" activities, such as sports. The 1930s and 1950s examples in Figure 10 are illustrative. The first image shows a girl baking-performing a traditional, domestic female role, and the secomd image shows a boy 
gazing at a group of fighter planes. In the latest two periods, both girls and boys are involved in a much wider range of activities beyond traditional gender roles, and they are shown actively and equally engaged in activities involving mathematical calculations (see also gender and activity images in Figure 2 and 12).

HELPING AT HOME

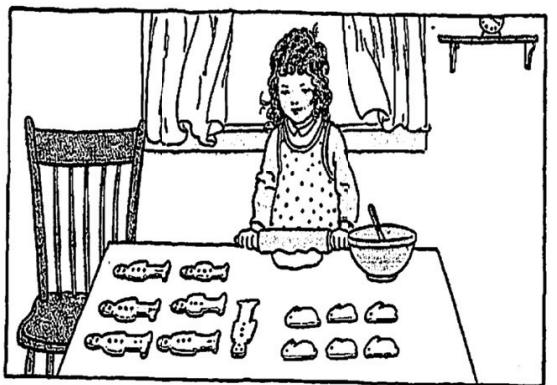

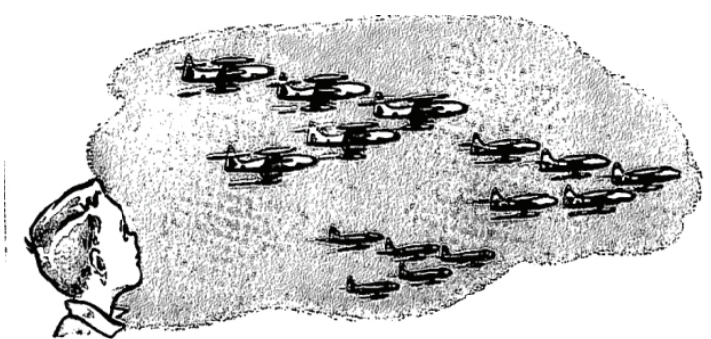

Figures 10. Examples from early textbooks depicting boys and girls in traditional gender roles. (Number Games and Stories, 1930, Grade 2; Growth in Arithmetic, 1952, Grade 3)

\subsection{Peopled Images and Cognitive Empowerment}

Figure 11 displays the trends in images of people coded as passive, active and unrelated to math as percent of the total pages. The overall findings show a relatively stable distributtion among the three categories across the century until the 1980s. Prior to this period, interestingly the majority of peopled images (ranging anywhere from 65 to 85 percent, depending on the period) showed them doing things unrelated to math. In contrast, over the century images coded as passive math were the least common, never exceeding 15 percent and slowly decreasing since the 1960 s so that in the last decade of the century they were only $1.5 \%$ of the total images. Images of students as active math agents were in each period somewhere between passive and unrelated to math. In contrast to the 1980s, when the active math category accounted for just $8 \%$ of all peopled images, that proportion rises dramatically during the $1990 \mathrm{~s}$, to $46 \%(\mathrm{t}=4.538, \mathrm{p}=.002)$. This significant increase mirrors a similar, yet smaller, gain in active math portraits that occurred during the 1964-1971 period (when active math images reached 30 percent of all peopled images) that rapidly disappeared in the 1970s and 1980s. But overall as a percent of the total images people actively engaged in math rose in the last decade of the century, the other two categories declined, so that by 1999 as peopled images grew to $40 \%$ of all images, they were equally split between portraying active engagement in math and unrelated activates.

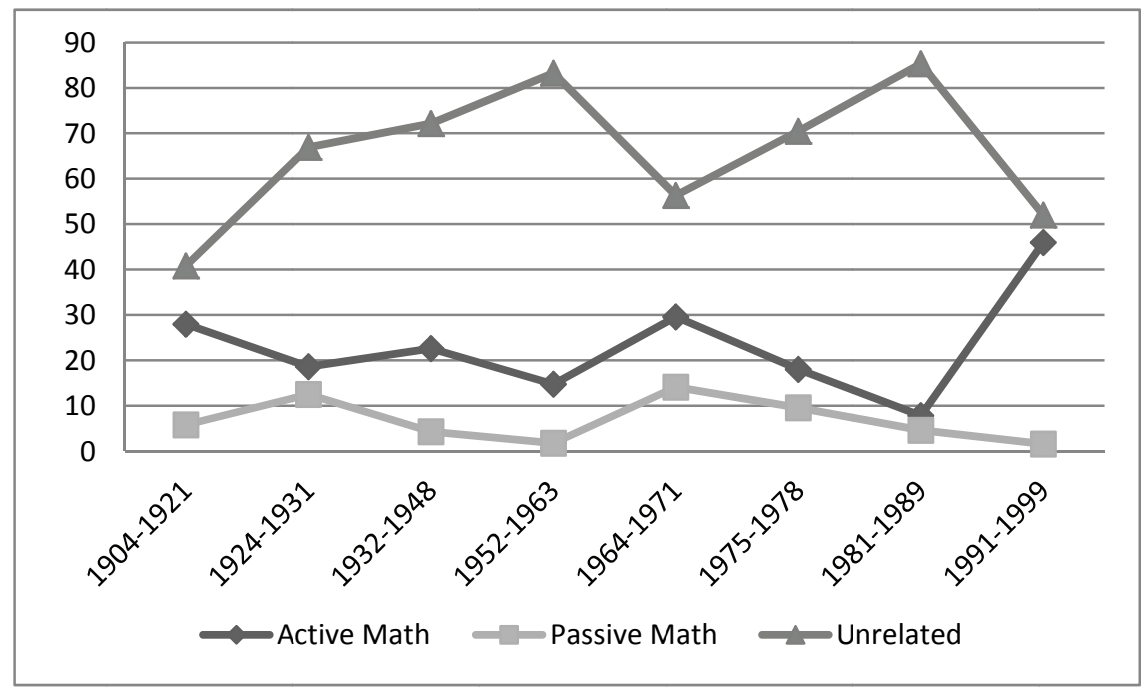

Figure 11. People's relationship to math in images as percent of total images, 1904-1999 
All of these trends synergistically culminate in the heavily imaged textbook of the 1990s, where images similar to of the 1991 example in Figure 12 appear. Here is a scene of racial inclusivity, equal gender roles, and active engagement in the process of learning and applying complex math skills such as mental math.

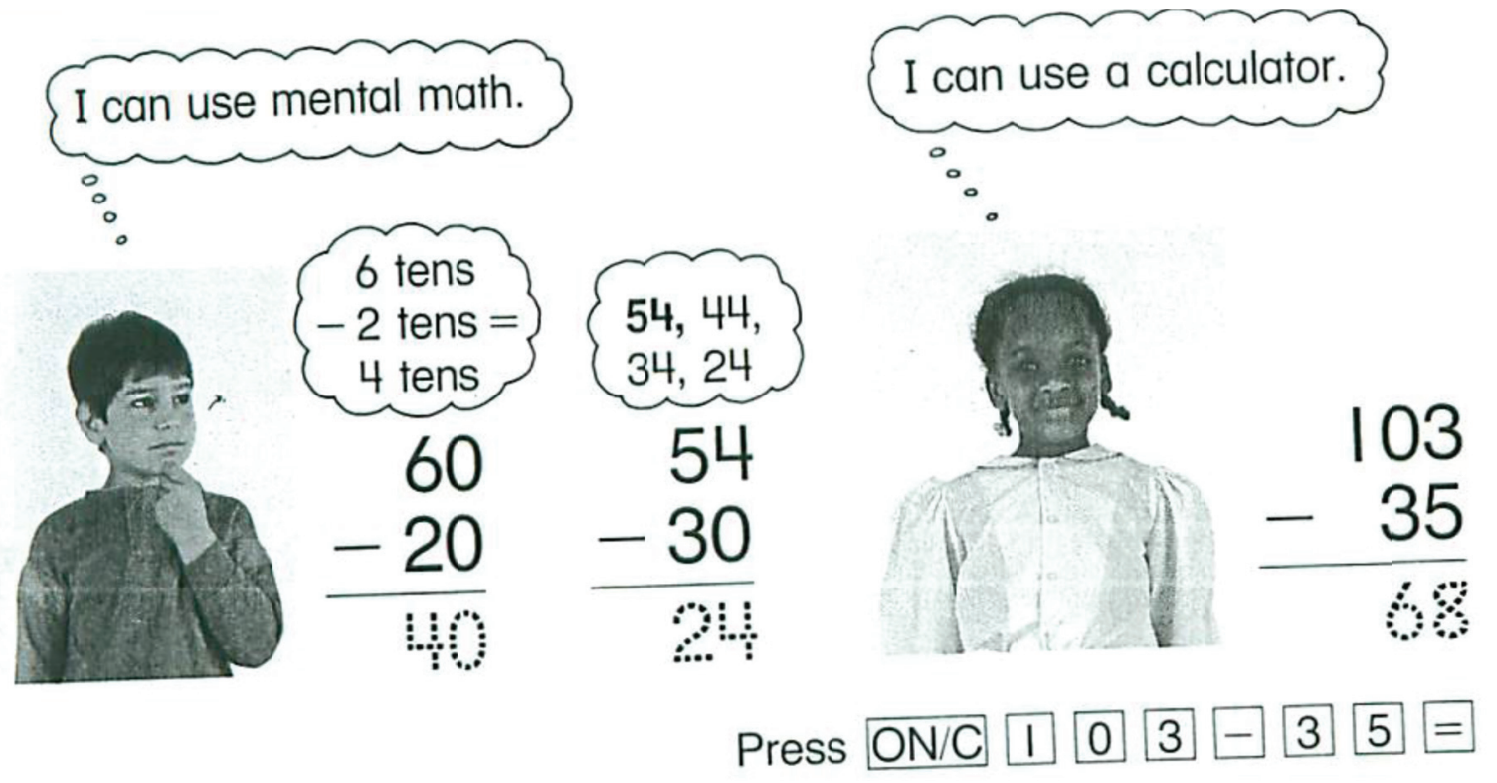

Figure 12. Problem solving source: Addison Wesley 1991, grade 2, p.303

\section{Conclusion}

There are multiple implications of these results from a systematic assessment of the visual hidden curriculum in early grade math textbooks, and the main trends and their interactions shown here enhance the arguments and conclusions from earlier theory and research. First is the documentation of the significant rise in volume of visual hidden curriculum that expanded with the length of math textbooks. The increased size of textbooks is potentially the result of many factors. Increased textbook size might be the direct result of institutional changes in education related to students spending more time in school and extended instructional programs. The average number of days that enrolled students attended school rose systematically during the early decades of the 20th century in the United States (1900: 98 days, 1920: 121 days, 1930: 143 days), reaching contemporary levels by the end of the 1940s (1949: 160 days) [52]. Similarly, the average length of the school year or term lengthened to 175 days by the 1940s, almost as long as today. As Sonnenberg observes, "the increase in the number of school days for the average student during the early 20th century meant that a more extensive instructional program could be provided" [53](p. 27). It makes sense then that textbooks grew in size to correspond with the increase in school days and the expansion of the instructional program. Additionally the centrality of schooling and its demands on all children to be enrolled and to be exposed to academic curricula fueled the growth of textbooks. Also factors such as technological improvements that allowed faster and cheaper printing, a burgeoning professional field of education and instruction, and even rising GDP all likely contributed to increased textbook size.

Clearly the math textbook for primary schooling experienced the general semiotic revolution that influenced all types of public documents over the $20^{\text {th }}$ century. And the increasing volume of iconic images found here means that compared to early in the century, contemporary students of math, a topic often assumed to be sparse in cultural context, are exposed to high volumes of hidden curricular material [50][54]. This massive channel of hidden curriculum in turn gives greater weight to the cultural messages contained in them. For some scholars, the "hidden curriculum" reinforces the ideological hegemony of powerful groups or social classes thus reproducing the social structure; while others see it as the site of on-going struggles between hegemonic and counterhegemonic values, and forces that both 
result from and influence social and cultural change [55][25]. At the same time, sociologists of education and visual researchers have also analyzed textbook images as a way to document cultural and curricular changes over recent decades [43][1][2][3][5][44]. One perspective is that the textbook content is a normative expression of shared ideas, values, and meanings that exist at the root of schooling as a social institution and enhance social solidarity and cohesion [56][57][58]. Seen this way, the greatly expanded visual content in math is one medium by which schooling's extensive culture of education communicates its messages.

Along with the richer semiotic environment is the "peopling" of math textbooks images. And who the people are and what they are doing summarizes the messages to the student of an expanding visual hidden curriculum. As schooling and its institutional culture expanded over the $20^{\text {th }}$ century, textbook content evolved with the socially constructed notions of gender, race and ethnicity, as well as the very essence of the meaning of student. The analysis reveals that in the United States early elementary mathematics textbook images expanded and evolved, and now promote messages of social inclusivity and cognitive empowerment. At the beginning of the century a typical primary school mathematics textbook had less than 150 pages, approximately a quarter of them included images, few of those images featured people, and they lacked diversity and included stereotypes. In the middle of the century during the 1950s and the politically contentious 1960s - the visual presence of humans decreased, only to re-appear much more prominently in the last third of the century. As earlier research also found, this process was resisted in the middle of the century to some degree in an indirect fashion [10]. For example, "an abundance of humanoid animals dressed in human garb", or eliminating human figures altogether, was a strategy used by textbook publishers to avoid charges of biased gender or racial representation that were highly contentious during the 1960s and 1970s [37]. By the 1990s, a typical early elementary mathematics textbook had significantly more pages, most of which included images, around a third of the images included people, and the representation of people was considerably more socially diverse in terms of racial/ethnic background and equitable in terms of gender roles than in earlier decades.

The record of the peopling of the visual hidden curriculum has implications for political theories and institutional theory of schooling. The historical record from earlier in the century adds support to the political hegemony perspective. Racial diversity as an underlying value did not gain expression in early mathematics textbooks until the second half of the century; in textbooks published prior to 1963 there were virtually no pictures of black Americans or other groups that were phenotypically different from the white majority. In addition, in the few instances in which racial minority groups, most often Native Americans, were represented, the images were stereotypical in ways that would be considered inappropriate, offensive or insensitive by contemporary values. And as noted, textbook images became less peopled as issues of diversity and equality became more contentious in the middle of the century. But a hegemonic theory, however, suffers from the fact that an early conservative hidden curriculum gives way to a far more inclusive visual message over the last third of the century.

At the same time, visual content correlates with the institutional development of public schooling. The links among the observed trends in visual content, the cultural or normative ideas embodied by such images, and the structural and institutional transformations in American education and society during the $20^{\text {th }}$ century may be a more encompassing and accurate perspective than the hegemony or counter-hegemony debate. This is evident here in three ways.

First, observed trends in textbooks images increasingly reflect an idea of the student that is embodied in and drives the process of expansion and institutionalization of mass education: the socially inclusive notion that everybody, regardless of gender, race or any other consideration, can and should be a student. Today we take this notion for granted, but the historical outlook that we have provided shows that gaining full social recognition has been a long journey. For example, although girls were represented in images in early elementary mathematics textbooks throughout the century, in earlier decades they were typically engaged in gender stereotypical roles [59]. In their analysis of all kinds of educational artifacts, Tyack and Hansot [60] found that by 1850 sharp gender disparities had narrowed and boys and girls went to school in similar proportions. But often referred to as the hidden curriculum, textbook images arguably socialized female students through sex-role stereotyping where girls were represented as passive and polite. Pesikan and Marinkovic [61] showed a movement toward greater gender equity in textbook images over a shorter and more recent historical period.

The absence of minority group representation in textbook images during the first half of the $20^{\text {th }}$ century is likely related to racist and poverty barriers to public school access in that time period, but it 
does not fully explain the absence. Historically, enrollment rates of non-whites in American public schools were significantly lower than those of whites, yet still substantial: in 1900 the percent black and other races enrolled was 31 percent, as compared to 54 percent for whites [52]. The gap in participation in elementary education closed slowly but progressively over time, thus enrollment records cannot fully explain the complete absence of African Americans in textbook images prior to the 1960s. Public schooling expanded rapidly over the $20^{\text {th }}$ century, as diverse groups of people increasingly challenged barriers and participated in schooling, it appears that textbook publishers opted to include the politically and socially neutral images of non-human students and teachers for two decades before fully embracing the new face of the American public. In the 1964-1971 period, the average proportion of images of non-white people increased, and sharply, for the first time. The specific timing of this sudden change suggests an important role of the Civil Rights Movement, which in its educational front challenged not only the racial segregation of schools, but also the use of instructional materials that might diminish the self-esteem of black students [62].

Typical textbook policy now includes ethnic and cultural groups, older persons, and people with disabilities. For example, Florida's "Priorities for Evaluating Instructional Materials" [63] states that "portrayal of gender, ethnicity, age...and various social groups must include multicultural fairness and advocacy." Most recently, as images of students take up more textbook space, publishers have begun to set numerical targets for showing minorities and the disabled and also customize the racial composition of textbooks for individual states. In one publisher's guidelines for artwork and photos, they stipulate that

"...Asians should not be portrayed "with glasses, bowl-shaped haircuts, or as intellectuals"; African-Americans should be shown "in positions of power, not just in service industries"; elderly people should be "active members of society," not "infirm"; and disabled people should be shown as independent rather than receiving help. An older ...manual...discourages depicting Asian-American males as waiters, laundry owners or math students, or showing Mexican men wearing ponchos or wide-brimmed hats." [64].

Second, contemporary textbooks have changed in the direction of encouraging students to understand themselves as individuals capable of complex intellectual activities, fostering personal empowerment based on these enhanced capabilities-cognitive empowerment. Today, even elementary students are invited to believe in their individual capacities and exposed to the message that they can become, indeed are supposed to become, practicing, thinking mathematicians themselves. Included in this message is that everyone is welcome to use math, can learn it, and be active users of its principles. Over the course of the century, the image of learning math has gone from one of a technical skill to be accomplished in a somewhat passive mechanical fashion as evidenced by the images of students' passive contemplation of adults' academic performance to an active cognitive pursuit open to all students.

Lastly, the visual hidden curriculum in these textbooks reflects underlying changes in primary school mathematics. As described above, the main trends leading to the more abstract, conceptual, and reasoning-based approaches to mathematical thinking textbook likely also shaped what is occurring in peopled images [17]. From the 1930's images of white middle-class children using a rhyme to teach numbers to the 1990's image of a diverse group of children representing the concept of a number in different ways, the hidden curriculum becomes filled with active math. And the difference in message is profound: a 1929 textbook lesson on informal geometry accompanied by the image of shapes and plane figures, versus the same lesson in a 1990's text with the image of a racially-ethnically inclusive, male and female, physically varied group of students solving geometry problems that require mental rotation and the translation of three-dimensional shapes to plane figures. These visual trends follow some of the overarching trends of "new math" in the Sputnik era, and then in debates about National Council of Teachers of Mathematics' standards. The contemporary textbook is filled with images of a diverse range of students frequently depicted as "little mathematicians" who independently think about math, employ multiple strategies to solve mathematical problems, pursue more complex calculations and make mathematical decisions [65].

Textbooks did not have to change in the way that they did; for example, they could have included fewer images of people and used the textbook space to focus solely on presenting content. The fact that more diverse and more mathematically engaged people are featured in images than in the past is an 
indicator of the larger normative trend of inclusion of different socio-demographic groups as active participants of the educational process, and of ideas about schooling in general. Changes related to primary visual communication in contemporary culture also might have provided a propitious context for the observed trends. But textbook images reflect the socially constructed roles of society and these shared meanings are dynamic, they have evolved over time. As schooling expanded over the $20^{\text {th }}$ century, it gained institutional strength and evolved its notions and representation of the student.

\section{References}

1. J. P. Gee, Social Linguistics and Literacy: Ideology in Discourses, New York, Routledge, 2007.

2. G. Kress, Multimodality: A Social Semiotic Approach to Contemporary Communication. New York: Routledge, 2009.

3. G. Kress, "Multimodality: Challenges to thinking about language," TESOL Quarterly, 34, 337-340, 2000.

4. T. Royce, "Multimodality in the TESOL Classroom: Exploring Visual-Verbal Synergy," TESOL Quarterly, Vol. 36, No. 2 (Summer), pp. 191-205, 2002.

5. L. Pauwels, "Visual sociology reframed: An analytical synthesis and discussion of visual methods in social and cultural research," Sociological Methods 83 Research, 38(4): 545-581, 2010.

6. J. Alexander, D. Bartmanski, and B. Giesen, Iconic power: materiality and meaning in social life. Palgrave MacMillan, 2012.

7. R. Nathansohn, and D. Zuev (Eds.). The sociology of the visual sphere. Routledge, 2013.

8. G. Kress, and T. van Leeuwen, Reading images: The grammar of visual design. Routledge, 1996.

9. J.A. Laspina, The Visual Turn and the Transformation of the Textbook. Lawrence Erlbaum Associates, 1998.

10. P. Mulcahy and S. J. Samuels, "Three hundred years of illustrations in American textbooks," In The psychology of illustration (pp. 1-52). Springer, 1987.

11. M.A. Evans, C. Watson, and D. M. Willows, "A naturalistic inquiry into illustrations in instructional textbooks," In The psychology of illustration (pp. 86-115). Springer US, 1987.

12. A. A. Cuoco and F. R. Curcio, (Eds.), The roles of representation in school mathematics. National Council of Teachers of Mathematics, 2001.

13. J. R. Levin and R. E. Mayer, "Understanding illustrations in text," Learning from textbooks: Theory and practice, 95-113, 1993.

14. C. Misailidou and J. Williams, "Children's arguments in discussion of a "difficult" ratio problem: the role of a pictorial representation," In Proceedings of the $3 \mathrm{rd}$ Conference of the European Society for Research in Mathematics Education (CERME3), 2003.

15. J. Peeck, "Increasing picture effects in learning from illustrated text," Learning and instruction, 3(3), 227-238, 1993.

16. F. Stylianidou, "Analysis of science textbook pictures about energy and pupils' readings of them," International Journal of Science Education, 24(3), 257-283, 2002.

17. D. P. Baker, D., Knipe, H., Cummings, E., Collins, J., Leon, J. Blair, C., and D. Gamson, "One Hundred Years of American Primary School Mathematics: A Content Analysis and Cognitive Assessment of Textbooks from 1900 to 2000." Journal of Research on Mathematics Education, 41, 4, 383-423, 2010.

18. E. F. Donoghue, "Algebra and geometry textbooks in twentieth-century America," In G. M. A. Stanic \& J. Kilpatrick (Eds.), A history of school mathematics (Vol. 1, pp. 329-398). National Council of Teachers of Mathematics, 2003.

19. R. F. Nicely, "Higher-order thinking skills in mathematics textbooks: A research summary," Education, 111(4), 456-460, 1991.

20. N. Sinclair, The history of the geometry curriculum in the United States. Information Age, 2008.

21. R. Stevens, Lu, X., Baker, D., Ray, M., Eckert, S., \& D. Gamson, "Assessing the Cognitive Demands of Elementary School Reading Curricula: An Analysis of Reading Text and Comprehension Tasks from 1910 to $2000 . "$ American Education Research Journal, Vol. 52, No. 3, pp. 582-617, 2015.

22. A. C. Porter, "Curriculum assessment," In Complementary methods for research in education (3rd edition). AERA, 2006.

23. M. Apple, Teachers and Texts: A political economy of class and gender relations in education. Routledge, 1986. 24. E. Ellsworth and M. H. Whatley, The ideology of images in educational media: hidden curriculums in the classroom. Teachers College Press, 1990. 
25. S. L. Wong, "School textbooks and cultural authority," Education and sociology: An encyclopedia, 533-537. 2002. 26. R. M. Elson, Guardians of tradition: American schoolbooks of the nineteenth century. Vol. 553: University of Nebraska Press, 1964.

27. F. Fitzgerald, America revised: History schoolbooks in the twentieth century: Little, Brown, 1979.

28. J. Anyon, "Ideology and United States history textbooks," Harvard Educational Review no. 49 (3):361-386, 1979. 29. J. W. Loewen, Lies my teacher told me: Everything your American textbook got wrong. Simon and Schuster. 1995.

30. C. E. Sleeter and C. A. Grant, "Race, class, gender and disability in current textbooks," In Eugene F. Provenzo, Jr., Annis N. Shaver, Manuel Bello (editors), The textbook as discourse. Sociocultural dimensions of American schoolbooks, 183-215, 2011.

31. S. L. Wong, "Evaluating the content of textbooks: Public interests and professional authority," Sociology of Education:11-18, 1991.

32. D. Nelkin, Science textbook controversies and the politics of equal time. MIT Press, 1977.

33. J. J. Good, J. A. Woodzicka, and L. C. Wingfield, "The effects of gender stereotypic and counter-stereotypic textbook images on science performance," The Journal of social psychology, 150(2), 132-147, 2010.

34. E. F. Provenzo Jr, A. N. Shaver, and M. Bello, The Textbook as Discourse: Sociocultural Dimensions of American Schoolbooks. Routledge, 2011.

35. A. Wolf, "Minorities in U.S. History Textbooks, 1945-1985," The Clearing House, 65(5), 291-297, 1992.

36. J. Garcia, "The portrayal of females and minorities in selected elementary mathematics series," School Science and Mathematics, 90, 1, pp. 2-12, 1990.

37. B. Steele, "Sexism in Math Texts," Edcentric (Spring/Summer), 17-19, 60, 1977.

38. R. Lerner, Molding the Good Citizen. The Politics of High School History Texts. Praeger Publishers, 1995.

39. J. W. Meyer, "The effects of education as an institution," American journal of Sociology, 55-77, 1977.

40. J. D. Marshall, "With a little help from some friends: Publishers, protesters, and Texas textbook decisions," In The Politics of the Textbook, Routledge, 1991.

41. Tyson-Bernstein, Harriet, and Arthur Woodward. "Nineteenth century policies for twenty-first century practice: The textbook reform dilemma," In Textbooks in American society, State Universiy of New York Press, 1991.

42. P. Bromley, J. W. Meyer, and F. O. Ramirez, "The Worldwide Spread of Environmental Discourse in Social Studies, History, and Civics Textbooks, 1970-2008," Comparative Education Review. 2012.

43. P. Bromley, J. W. Meyer, and F. O. Ramirez, "Student-Centeredness in Social Science Textbooks, 1970-2008: A Cross-National Study," Social Forces, 90, 2, pp. 547-570, 2011.

44. J. W. Meyer, P. Bromley and F. O. Ramirez, "Human Rights in Social Science Textbooks: Cross-national Analyses, 1970-2008," Sociology of Education, 83(2) 111-134, 2010.

45. E. H. McEneaney, "Elements of a Contemporary Primary School Science," In Science in the Modern World Polity: Institutionalization and Globalization, 2003.

46. A. Bock, H. Iserman and T. Knieper, "Quantitative Content Analysis of the Visual," in Margolies and Pauwell (editors), The SAGE Handbook of Visual Research Methods. SAGE, 2011.

47. K. A. Neuendorf, The Content Analysis Guidebook. SAGE, 2002.

48. D. Tyack and L. Cuban, Tinkering Towards Utopia: A Century of Public School Reform. Harvard University Press, 1997.

49. R. Bain, "Rounding up unusual suspects: Facing the authority hidden in the history classroom," The Teachers College Record no. 108 (10):2080-2114, 2006.

50. P. Dowling, The sociology of mathematics education: mathematical myths, pedagogic texts. The Falmer Press, 1998.

51. I. Esmonde, "Snips And Snails And Puppy Dogs' Tails: Genderism And Mathematics Education," For the Learning of Mathematics 31, 2 (July), 2011.

52. T. D. Snyder, "120 Years of American Education: A Statistical Portrait. National Center for Education Statistics," Accessed at http://nces.ed.gov/pubs93/93442.pdf, 1993.

53. W. Sonnenberg, "Elementary and Secondary Education," In Snyder, T.D. (1993). 120 Years of American Education: A Statistical Portrait. National Center for Education Statistics, 1993.

54. J. Prosser (Ed.), Image-based research: a sourcebook for qualitative researchers. Falmer Press, 1998.

55. M. Apple, Ideology and curriculum. Routledge, 2004

56. E. Durkheim, The evolution of educational thought: Routledge and Kegan Paul, 1977.

57. T. Parsons, "The school as a social system: some of its functions in American society," Harvard Educational Review 29, 297-318, 1959. 
58. R. Dreeben, On What Is Learned in School. Massachusetts: Addison-Wesley Publishing Company, 1968.

59. J. N. Burstyn and R. R. Corrigan, "Images of Women in Textbooks, 1880-1920," Teachers College Record, 76, pp. 431-440, 1975.

60. D. Tyack and E. Hansot, Learning Together: A History of Coeducation in American Schools. Yale University Press, 1990.

61. A. Pešikan and S. Marinković, "A comparative analysis of the image of man and woman in illustrations of textbooks for first grade children," Psihologija, 39(4), 383-406, 2006.

62. J. T. Patterson, Brown v. Board of Education: A Civil Rights Milestone and Its Troubled Legacy. Oxford University Press, 2001.

63. Florida Department of Education, Priorities for Evaluating Instructional Materials: Research Update. Accessed http://www.cimes.fsu.edu/files/researchReport.pdf, 2008.

64. D. Golden, "Aiming for Diversity, Textbooks Overshoot," Wall Street Journal, 2006.

65. M. Lampert and D. L. Ball, Teaching, Multimedia, and Mathematics: Investigations of Real Practice. The Practitioner Inquiry Series. Teachers College Press, 1998.

\section{Appendix A. Selected Mathematics Textbooks and Textbook Series by Historical Period}

\begin{tabular}{|c|c|c|}
\hline Title & Publisher & Years Published \\
\hline \multicolumn{3}{|l|}{ 1904-1921 } \\
\hline The New Stone-Millis Arithmetics & BH Sanborn & 1910-1921 \\
\hline Wentworth-Smith Mathematical Series: School Arithmetics & Ginn \& Co. & $1907-1914$ \\
\hline Southworth Stone Arithmetic & BH Sanborn & 1904-1908 \\
\hline The Stone Millis Arithmetic & BH Sanborn & $1910-1921$ \\
\hline First Journeys in Numberland & Scott Foresman & 1911 \\
\hline \multicolumn{3}{|l|}{$1924-1931$} \\
\hline Strayer-Upton Arithmetic & American Book Co. & $1924-1931$ \\
\hline A Child's Book of Number & BH Sanborn & 1924 \\
\hline Number Games and Stories & Houhgton Mifflin & 1930 \\
\hline Walks and Talks in Numberland & Ginn and Co. & 1929 \\
\hline \multicolumn{3}{|l|}{$1932-1948$} \\
\hline Daily-Life Arithmetics & Ginn and Co. & 1938 \\
\hline Living Arithmetic & Ginn and Co. & $1943-1951$ \\
\hline Study Arithmetic & Scott Foresman & $1934-1348$ \\
\hline Jolly Numbers & Ginn and Co. & 1937-1959 \\
\hline Number Stories & Scott Foresman & $1932-1947$ \\
\hline \multicolumn{3}{|l|}{$1948-1963$} \\
\hline Growth in Arithmetic & World & $1952-1956$ \\
\hline Making Sure of Arithmetic & Silver Burdett & 1946-1958 \\
\hline Moving Ahead in Arithmetic & Holt, Rinehart, and Winston & 1963 \\
\hline Arithmetic We Need & Ginn \& Co. & $1955-1963$ \\
\hline Seeing Through Arithmetic (A) & Scott Foresman & 1956-1963 \\
\hline Our Number Workshop & Scott Foresman & $1952-1961$ \\
\hline Numbers We Need & Ginn \& Co. & $1955-1963$ \\
\hline Jolly Numbers & Ginn \& Co. & $1937-1959$ \\
\hline \multicolumn{3}{|l|}{ 1964-1971 } \\
\hline Elementary School Mathematics & Addison-Wesley & 1968-1971 \\
\hline Seeing Through Arithmetic & Scott Foresman & 1964-1968 \\
\hline \multicolumn{3}{|l|}{$1974-1978$} \\
\hline Holt School Mathematics & Holt, Rinehart, and Winston & $1974-1978$ \\
\hline Mathematics Around Us & Scott Foresman & $1975-1978$ \\
\hline
\end{tabular}




\begin{tabular}{lll}
\hline 1981-1991 & & \\
Addison-Wesley Mathematics & Addison-Wesley & $1985-1995$ \\
Holt Mathematics & Holt, Rinehart, and Winston & $1974-1978$ \\
Houghton Mifflin Mathematics & Houghton Mifflin & $1983-1991$ \\
\hline 1991-2000 & & \\
Silver Burdett Ginn Mathematics & Silver Burdett & $1999-2001$ \\
Addison Wesley Math & Addison Wesley & $1985-1995$ \\
\hline
\end{tabular}

\section{Appendix B: Descriptive Data}

Table 1. Textbook pages, pages including images, and pages including images of people, 1904-1999, grades $\mathrm{K}-3$

\begin{tabular}{|c|c|c|c|c|c|c|c|c|c|c|c|c|}
\hline \multicolumn{2}{|c|}{ Textbooks } & \multicolumn{3}{|c|}{ Textbook Pages (TP) } & \multicolumn{4}{|c|}{ Pages Including Images (PII) } & \multicolumn{4}{|c|}{ Pages with Images Of People (IOP) } \\
\hline & $\mathrm{N}$ & $\mathrm{N}$ & Mean & St Dev & $\mathrm{N}$ & Mean & St Dev & $\begin{array}{c}\text { PII as } \% \\
\text { of TP }\end{array}$ & $\mathrm{N}$ & Mean & St Dev & $\begin{array}{c}\text { IOP as } \% \text { of } \\
\text { PII }\end{array}$ \\
\hline 1904-1921 & 8 & 1,100 & 138 & 77.75 & 239 & 30 & 21.05 & 21.7 & 99 & 12 & 11.89 & 41.4 \\
\hline 1924-1931 & 6 & 984 & 164 & 85.37 & 386 & 64 & 42.22 & 39.2 & 209 & 35 & 22.64 & 54.1 \\
\hline 1932-1948 & 5 & 1,354 & 271 & 80.76 & 629 & 126 & 25.88 & 46.5 & 340 & 68 & 30.66 & 54.1 \\
\hline $1952-1963$ & 18 & 3,398 & 189 & 100.6 & 2,303 & 128 & 45.28 & 67.8 & 822 & 46 & 25.27 & 35.7 \\
\hline 1964-1971 & 5 & 1,280 & 256 & 68.21 & 655 & 131 & 64 & 51.2 & 102 & 20 & 21.51 & 15.6 \\
\hline $1975-1978$ & 7 & 1,770 & 253 & 112.3 & 1,401 & 200 & 88.72 & 79.2 & 216 & 31 & 23.73 & 15.4 \\
\hline 1981-1989 & 10 & 3,021 & 302 & 94.02 & 2,602 & 260 & 73.28 & 86.1 & 604 & 60 & 32.44 & 23.2 \\
\hline 1991-1999 & 8 & 2994 & 374 & 105.6 & 2,249 & 281 & 119.1 & 75.1 & 836 & 105 & 50.22 & 37.2 \\
\hline Total & 67 & 15,901 & & & 10,464 & & & & 3,228 & 48 & & \\
\hline
\end{tabular}

Table 2. Non-white and female as percentage of total images, 1904-1999, grades K-3

\begin{tabular}{ccccc}
\hline & \multicolumn{2}{c}{ \% Non-white } & \multicolumn{2}{c}{ \% Female } \\
& Mean & St Dev & Mean & St Dev \\
\hline $1904-1921$ & 2.82 & 6.10 & 38.78 & 25.73 \\
$1924-1931$ & 1.74 & 2.40 & 49.47 & 4.35 \\
$1932-1948$ & 0.19 & 0.24 & 42.83 & 4.23 \\
$1952-1963$ & 0.82 & 0.66 & 44.68 & 7.87 \\
$1964-1971$ & 14.49 & 16.01 & 42.25 & 8.35 \\
$1975-1978$ & 30.57 & 9.38 & 49 & 4.28 \\
$1981-1989$ & 22.29 & 7.30 & 47 & 3.62 \\
$1991-1999$ & 34.25 & 6.39 & 49 & 2.35 \\
\hline
\end{tabular}


Table 3. People's relationship to math as percent of total images, 1904-1999, grades K-3

\begin{tabular}{ccccccc}
\hline & \multicolumn{2}{c}{ \% Unrelated } & \multicolumn{2}{c}{ \% Passive } & \multicolumn{2}{c}{ \% Active } \\
Period & Mean & St Dev & Mean & St Dev & Mean & St Dev \\
\hline $1904-1921$ & 40.81 & 27.72 & 5.84 & 10.44 & 27.97 & 18.19 \\
$1924-1931$ & 66.91 & 18.43 & 12.50 & 19.29 & 18.63 & 10.03 \\
$1932-1948$ & 72.15 & 12.26 & 4.30 & 3.07 & 22.59 & 12.38 \\
$1952-1963$ & 83.27 & 12.44 & 1.78 & 3.08 & 14.77 & 12.86 \\
$1964-1971$ & 56.31 & 26.92 & 14.10 & 17.63 & 29.59 & 27.66 \\
$1975-1978$ & 70.46 & 22.19 & 9.58 & 13.88 & 18.01 & 13.25 \\
$1981-1989$ & 85.33 & 10.24 & 4.63 & 5.36 & 7.83 & 7.12 \\
$1991-1999$ & 52.02 & 24.26 & 1.59 & 2.38 & 45.98 & 22.91 \\
\hline
\end{tabular}

